\title{
A DYNAMICAL STUDY OF SALINE PLUMES IN DESALINATION OUTFALLS
}

\author{
SHAYMAA MUKHLIF SHRAIDA (D)
}

(Received 2 December 2021; first published online 1 March 2022)

\begin{abstract}
2020 Mathematics subject classification: primary 76B07; secondary 76B70, 76D05.
\end{abstract}
Keywords and phrases: fluid dynamics, gravity current, desalination, out-flow.

This thesis discusses the outflow of high-salinity water into the ocean from a source either situated on or elevated above the ocean floor. This is important to gain a better understanding of the outfalls from desalination plants that return the used water back to the ocean. It was found that the brine discharged from desalination plants is always warmer and saltier than the ambient ocean water. This means that it is most likely to flow out along the bottom as a gravity current of salty water, with the potential for damage to both fish and plant life, and, as such, it is a threat to the marine environment. We begin with a simple, steady, two-dimensional model of flow from a single line source elevated above a horizontal base and consider its downward flow into a spreading layer on the bottom. Linear solutions are obtained for high flow rates and full nonlinear solutions are obtained over a range of parameter values. It is found that there is a minimum flow rate beneath which no steady solutions of this type exist. This flow serves as a model for a two-dimensional water fountain or it approximates a similar flow in a density stratified environment. In addition, we use the same model to consider the outflow of water from the peak of a triangular ridge into a channel of finite depth at small flow rates. A numerical method is used to compute the shape of the density interface and it is found for this case, there is a maximum flow rate beyond which steady solutions do not seem to exist. To extend this work and consider how the steady flows develop, we use a spectral method to solve the viscous Boussinesq equations and study the unsteady flow of a plume of heavy fluid into a lighter fluid when the source is located on the bottom. A small initially circular 'bubble' grows for small time and then increases up to some height before it levels off and starts to flow outwards horizontally. We discuss these results for different values of Reynolds number, flow rate and density differential, and relate this full detailed model to the

Thesis submitted to Murdoch University in November 2020, degree approved on 23 June 2021, principal supervisor Graeme Hocking, cosupervisor Mark Lukas.

(C) The Author(s), 2022. Published by Cambridge University Press on behalf of Australian Mathematical Publishing Association Inc. 
idealised flows computed in the first section. Finally, the spectral method is extended to solve the viscous Boussinesq equations and to consider the unsteady flow from a source that is located off the bottom. It is found that there are four types of initial flow plume; separate, smooth, mushroom and blob, which depend on the source height and flow rate.

Parts of this research have been published in $[1,2]$.

\section{References}

[1] S. Shraida and G. Hocking, 'Flow from a source above a sloping base', ANZIAM J. 61 (2019), C75-C88.

[2] S. Shraida and G. Hocking, 'Potential flow of fluid from an elevated, two-dimensional source', J. Appl. Math. Model. 71 (2019), 349-362.

SHAYMAA MUKHLIF SHRAIDA, Department of Mathematics and Statistics, Murdoch University, Murdoch, Western Australia 6150, Australia

e-mail: shmath677@gmail.com 